\title{
Prevalence of hot flashes in women of 40 to 65 years of age with metabolic syndrome
}

\author{
Delena Proni Fonseca Saú1 \\ (iD)Ana Carolina Basso Schmitt ${ }^{2}$ \\ (iD) Maria Regina Alves Cardoso ${ }^{3}$ \\ (D) José Mendes Aldrighi
}

\begin{abstract}
1. Mestre, Departamento de Saúde Materno-Infantil, Faculdade de Saúde Pública, Universidade de São Paulo, SP, Brasil. 2. Ph.D, Departamento de Fisioterapia Fonoaudiologia e Terapia Ocupacional, Faculdade de Medicina, Universidade de São Paulo, SP, Brasil. 3. Ph.D, Departamento de Epidemiologia, Faculdade de Saúde Pública, Universidade de São Paulo, SP, Brasil.

4. Ph.D., Departamento de Saúde Materno-Infantil, Faculdade de Saúde Pública, Universidade de São Paulo, SP, Brasil;
\end{abstract}

http://dx.doi.org/10.1590/1806-9282.66.12.1628

\section{SUMMARY}

OBJECTIVE: Hot flashes have a negative impact on the quality of life of women during the menopausal transition and thereafter. The progressive reduction in gonadal estrogen levels associated with aging promotes an accumulation of abdominal fat, dyslipidemia, and arterial hypertension, all of which are components of metabolic syndrome (MetS). The objective of the present study was to estimate the prevalence of hot flashes and evaluate their relationship with MetS in women $\geq 40$ years of age.

METHODS: This was a cross-sectional study involving women aged between 40 and 65 years. We used the Kupperman index to quantify the climacteric symptoms and the National Cholesterol Education Program Adult Treatment Panel III criteria for the diagnosis of MetS.

RESULTS: 1,435 women were initially selected, and we obtained information from 647. The mean age at menopause was 45.99 years (SD 6.61 years) and the prevalence of hot flashes and MetS were 55.83\% (95\% Cl:52.35-59.25\%) and 46.29\% (95\% Cl: 44.75-52.53\%), respectively. We identified a positive association between MetS and hot flashes (OR 1.16; 95\% Cl: 1.01-1.33).

CONCLUSIONS: In women $\geq 40$ years of age, hot flashes are highly prevalent and appear to be associated with MetS.

KEYWORDS: Climacteric. Perimenopause. Hot flashes. Metabolic syndrome.

\section{INTRODUCTION}

Metabolic syndrome (MetS) is highly prevalent, representing a major public health problem because it increases cardiovascular risk and results in significant costs to the health system'. Observational studies have suggested that MetS is three times more common in women $\geq 40$ years of age than in younger women ${ }^{2}$.

Hot flashes affect $50-80 \%$ of the female population during the menopausal transition and thereafter, reaching a peak between two years before and two years after menopause ${ }^{3,4}$. They are often associated with sleep disorders, changes in mood, and fatigue, which can impair the quality of life and generate high costs for health systems ${ }^{5,6}$. Because of fluctuations in ovarian function, many women $\geq 40$ years of age experience hot flashes and other manifestations such as accumulation of abdominal fat, obesity, and dyslipidemia, which are major components of MetS $^{2-4,7}$. 
Recent studies suggest that hot flashes signal a higher risk of cardiovascular disease (CVD), possibly due to activation of the sympathetic nervous system, which can alter blood pressure, the lipid profile, and insulin resistance ${ }^{8-10}$. Those factors, together with waist circumference, which is also often increased in women with hot flashes, constitute the diagnostic criteria for MetS ${ }^{11,12}$.

It is possible that the prevalence of hot flashes is higher in women with MetS, given that each of the constituents of the syndrome can, in isolation, be responsible for the onset of the vasomotor symptoms. Despite the isolated impact of the components of MetS on the triggering of hot flashes, some studies have shown that the relationship between vasomotor symptoms and MetS itself has been poorly investigated and that the few available findings are conflicting ${ }^{12-15}$. Therefore, the objective of the present study was to determine whether there is an association between hot flashes and MetS ${ }^{16}$.

\section{METHODS}

This was a cross-sectional study, based on information obtained from 7,212 women followed-up in 2014 via the Family Health Program in the city of Pindamonhangaba, Brasil, and stored in the Pindamonhangaba Health Care Project database. We selected the participants by probability sampling, using a systematic sampling procedure. The calculation of the ideal sample size, considering a 50\% prevalence of hot flashes ${ }^{3}$ and a maximum error of $5 \%$ in $95 \%$ of the possible samples, resulted in 384 individuals. We included women between 40 and 65 years of age. Women who did not complete the questionnaire employed for calculation of the Kupperman index (used in the investigation of hot flashes) were excluded, as were those who did not undergo laboratory tests, those who moved away from the study area, those for whom the data were incomplete or inconsistent, those who had cognitive deficits, and those who were using any oral contraceptives or hormone replacement therapy.

The variables studied were age; the level of education; religion; body weight; height; waist circumference; hip circumference; serum triglycerides, total cholesterol, low-density lipoprotein, and high-density lipoprotein; fasting glycemia; and blood pressure. For blood pressure measurements, we use a calibrated, digital, automated sphygmomanometer with an arm cuff (BP 3AG1; MicroLife AG, Widnau, Switzerland) that has been tested and validated by the British Hypertension Society, with the patient in a seated position and following the recommendations for the cuff size selection. We performed three blood pressure measurements on the left arm, at 1-min intervals, considering the mean of the last two measurements in our analysis. Hypertension was defined as a systolic blood pressure $\geq 130 \mathrm{mmHg}$ and a diastolic blood pressure $\geq 85 \mathrm{mmHg}^{17,18}$. We calculated the body mass index (BMI) by dividing the weight (in kilograms) by the height (in meters) squared $\left(\mathrm{kg} / \mathrm{m}^{2}\right)$, subsequently stratifying the patient status in accordance with the guidelines of the Brazilian Association for the Study of Obesity and Metabolic Syndrome ${ }^{17}$ : underweight (BMI $<18.5 \mathrm{~kg} / \mathrm{m}^{2}$ ); normal weight (BMI 18.5-24.9 kg/m²); overweight (BMI $\geq 25.0 \mathrm{~kg} / \mathrm{m}^{2}$ ); pre-obesity (BMI 25.0 $\left.29.9 \mathrm{~kg} / \mathrm{m}^{2}\right)$; class I obesity (30.0-34.9 kg/ $\left.\mathrm{m}^{2}\right)$; class II obesity (35.0-39.9 kg/m²); and class III obesity (BMI $\geq 40 \mathrm{~kg} / \mathrm{m}^{2}$ ). We also determined the smoking status of the patients. Using the Kupperman index, we classified the intensity of the menopausal symptoms as mild, moderate, or severe. A diagnosis of MetS was made based on the National Cholesterol Education Program Adult Treatment Panel III criteria ${ }^{18}$; that is, when at least three of the five following alterations are present: serum concentration of high-density lipoprotein cholesterol $<50 \mathrm{mg} / \mathrm{dL}$; waist circumference $>88 \mathrm{~cm}$; serum triglyceride concentration $\geq 150 \mathrm{mg} /$ dL; systolic blood pressure $\geq 130 \mathrm{mmHg}$ or diastolic blood pressure $\geq 85 \mathrm{mmHg}$; and fasting glycemia $\geq 110$ $\mathrm{mg} / \mathrm{dL}$. The dependent variable was the occurrence of hot flashes, whereas all other variables were analyzed as independent variables.

The women were interviewed by a well-trained team at primary health care clinics, where they were also submitted to the collection of blood samples for standardized laboratory tests. Those who did not appear for their scheduled appointments were interviewed in their homes and referred for the collection of blood samples. The data collection was supervised by a coordinator, and $10 \%$ of the interviews were repeated by telephone to reduce the risk of bias.

All blood samples were collected in the morning (after an $8 \mathrm{~h}$ fast), by the same nurse, using a 25 x 0.7 $\mathrm{mm}$, silicone-coated, tri-beveled, sterile $22-\mathrm{G}$ needle. The blood was collected into sterile, disposable, $16 \mathrm{x}$ $100 \mathrm{~mm}, 8 \mathrm{~mL}$ polyethylene terephthalate vacuum collection tubes (Vacuette; Greiner Bio-One, Kremsmünster, Austria), containing a clot activator and separator gel. The biochemical analysis was performed 
at the Pindamonhangaba Municipal Laboratory with commercial diagnostics kits (Roche Diagnostics, Mannheim, Germany) - that were submitted to automated analysis.

Statistical calculations were performed with the Stata SE statistical software package, version 12.0 (Stata Corp., College Station, TX, USA). Initially, we used descriptive statistics to analyze the data. We calculated the prevalence of hot flashes and that of MetS, with the respective $95 \%$ confidence intervals. We then calculated the odds ratio for MetS in relation to the dependent variable. Multiple logistic regression models were constructed to estimate the relative weight of each independent variable after adjustment for skin color, income, depression, anxiety, and smoking, all of which were considered potential confounders, and we calculated the adjusted odds ratios, together with the respective $95 \%$ confidence intervals.

In compliance with the requirements of Resolution 466/12 of the Brazilian National Ministry of Health ${ }^{19}$, the study was approved by the Research Ethics Committee of the University of São Paulo School of Public Health (CAAE: 64011917.3.0000.5421). All participants gave written informed consent.

\section{RESULTS}

Of the 1,435 women initially recruited, 513 were excluded because they did not complete the questionnaire employed for calculation of the Kupperman index, had cognitive deficits, or moved away from the study area. Of the remaining 900 women, 264 were excluded: 196 because they did not undergo the laboratory tests or because the related data were incomplete; and 59 because they were under 40 years old. Therefore, the final sample was comprised of 647 women.

Table 1 shows the characteristics of the study population. The prevalence of hot flashes was 55.83\% (95\% CI: 52.35-59.25\%), and the prevalence of MetS was 48.63\% (95\% CI: 44.75-52.53\%). Among the women evaluated, the mean age at menopause was 45.99 years (SD 6.61). In addition, the mean values for blood pressure, fasting glycemia, waist circumference, and BMI were above the desired levels ${ }^{19}$, translating to a high cardiovascular risk in the study population.

We found that a diagnosis of MetS increased the likelihood of the occurrence of hot flashes (crude OR 1.16; 95\% CI: 1.01-1.33). The odds ratio was adjusted for the potential confounders (skin color, income, depression, anxiety, and stress). In other words, women with
MetS were 16\% more likely to report hot flashes than those without the syndrome, confirming a positive association between MetS and hot flashes.

\section{DISCUSSION}

The hypoestrogenism that occurs during the menopausal transition can result in uncomfortable symptoms, such as hot flashes, which significantly impair the quality of life ${ }^{6,20}$. Clinically, hot flashes present as sudden-onset episodes of perceived overheating, typically in the trunk and face, resulting from an imbalance in thermoregulatory processes at the level of the hypothalamus in response to the reduction in estrogen levels. That imbalance causes the body to interpret small temperature oscillations as major changes, triggering cooling mechanisms such as flushing and sweating ${ }^{21}$. Recent studies suggest that hot flashes not only have a significant effect on the quality of life but also indicate a higher risk of CVD, possibly due to activation of the sympathetic nervous system.

In addition to a high prevalence of hot flashes (55.83\%), the present study showed high values for glycemia, blood pressure, waist circumference, and BMI, which indicate a higher risk of MetS and therefore of CVD. We also identified a clear association between complaints of hot flashes and MetS, a finding similar to those obtained in other studies ${ }^{12-14}$. That association can be explained by the increased sympathetic activity occurring in both conditions, as well as by obesity $^{22}$. This major cardiovascular risk factor, i.e., obesity, acts as an insulator, reducing the metabolic heat loss capacity ${ }^{12,23}$.

In a study involving 183 postmenopausal women, Lee et al. ${ }^{12}$ found that hot flashes were more common in women with MetS. Ryu et al. ${ }^{13}$ studied 1,906

TABLE 1. CHARACTERISTICS OF THE SAMPLE. SAÚ, HPF.

\begin{tabular}{l|l} 
Characteristic & $(N=647)$ \\
\hline Hot flashes $(\%)$ & 55.83 \\
\hline Metabolic syndrome (\%) & 48.63 \\
\hline Age (years), mean \pm SD & $50.65 \pm 8.49$ \\
\hline Age at menopause (years), mean & $45.99 \pm 6.61$ \\
\hline Systolic blood pressure (mmHg), mean \pm SD & $130 \pm 22.96$ \\
\hline Diastolic blood pressure $(\mathrm{mmHg})$, mean \pm SD & $80.10 \pm 14.31$ \\
\hline Glycemia (mg/dL), mean \pm SD & $103.11 \pm 41.87$ \\
\hline Waist circumference (cm), mean \pm SD & $93.44 \pm 12.48$ \\
\hline Body mass index (kg/m²), mean \pm SD & $29.54 \pm 5.51$ \\
\hline Monthly income (R\$), mean \pm SD & $1646.19 \pm 1155.81$ \\
\hline
\end{tabular}

R\$, Brazilian reals (exchange rate as of August 11, 2020: $R \$ 1.00=U S \$ 0.19$ ). 
postmenopausal women and also found that those with MetS were more symptomatic. Our results are also similar to those obtained in a study of 183 postmenopausal women conducted by Lee et al. ${ }^{12}$. In overweight or obese women and in those with a waist circumference greater than $88 \mathrm{~cm}$, we also observed a higher prevalence of hot flashes. That could be explained by the aforementioned insulating property of adipose tissue, which would trigger increases in body temperature. In our sample of younger women, we observed a higher frequency of hot flash complaints, especially in the two years surrounding the menopausal transition, which, in our sample, occurred at a mean age of approximately 46 years.

Since the present study had a cross-sectional design, we cannot make any inferences regarding causation or temporality among the variables studied. However, because we found an association between hot flashes and MetS, future studies could consider the occurrence of hot flashes as a risk marker for CVD and MetS. In fact, there have been numerous studies showing that hot flashes are associated with activation of the hypothalamic-pituitary-adrenal axis, with the release of cortisol, and with norepinephrine stimulation ${ }^{24,25}$. Therefore, the only way to establish causality among these factors in a more consistent manner is to conduct longitudinal cohort studies. There is evidence that sympathetic hyperactivity is a common denominator between MetS and the onset of hot flashes ${ }^{23,26}$. That is likely due to vascular phenomena resulting from the release of vasoactive substances (cortisol and norepinephrine), which is influenced not only by hypoestrogenism but also by the aging process $^{13}$. Finally, given the possibility of a relationship between hot flashes and MetS, as well as the known cardiovascular risk in women with MetS, it is recommended that immediate interventions be instituted in all women with hot flashes, especially those with risk factors for MetS.

The limitations of our study include its cross-sectional nature, as well as the losses during the sample collection phase and the recruitment of subjects only from the public health system, which might not adequately represent the general population. Those limitations create an opportunity for further, more complex, studies, which could confirm the data presented here.

\section{CONCLUSIONS}

In women of 40 years of age or older, hot flashes appear to be highly prevalent. There also appears to be a positive association between the occurrence of hot flashes and MetS.

\section{Funding/Support}

This work was supported by grants from the FAPESP - Fundação de Amparo à Pesquisa do Estado de São Paulo (Foundation for Research Support of the State of São Paulo)

\section{Author's Contributions:}

Helena Proni Fonseca Saú: data curation, formal analysis, methodology; Ana Carolina Basso Schmitt: conceptualization, data curation, formal analysis, funding acquisition, investigation, methodology, project management; Maria Regina Alves Cardoso: conceptualization, data curation, formal analysis, methodology, project management; José Mendes Aldrighi: conceptualization, data curation, investigation, methodology, project management.

Approved by the Research Ethics Committee of the University of São Paulo School of Public Health (CAAE: 64011917.3.0000.5421). 


\section{RESUMO}

OBJETIVO: As ondas de calor têm um impacto negativo na qualidade de vida das mulheres no climatério. A redução progressiva dos níveis de estrogênio gonadal associada ao envelhecimento promovem o acúmulo de gordura abdominal, dislipidemia e hipertensão arterial, componentes da síndrome metabólica (SM). O objetivo do presente estudo foi estimar a prevalência de ondas de calor e avaliar sua relação com $S M$ em mulheres com idade $\geq 40$ anos.

MÉTODOS: Estudo transversal envolvendo mulheres entre 40 e 65 anos de idade. Utilizamos o índice de Kupperman para quantificar os sintomas climatéricos e os critérios do National Cholesterol Education Program Adult Treatment Panel III para o diagnóstico de SM.

RESULTADOS: Mil, quatrocentas e trinta e cinco mulheres foram selecionadas inicialmente e obtivemos informações de 647. A idade média da menopausa foi de 45,99 anos (DP 6,61 anos) e a prevalência de ondas de calor e SM foi de 55,83\% (95\% Cl:52,35-59,25\%) e 46,29\% (95\% Cl: 44,75-52,53\%), respectivamente. Identificamos uma associação positiva entre SM e ondas de calor (OR 1,16; IC95\%: 1,01-1,33).

CONCLUSÕES: Em mulheres com idade $\geq 40$ anos, as ondas de calor são altamente prevalentes e parecem estar associadas a SM.

PALAVRAS-ChaVE: Climatério. Perimenopausa. Fogachos. Síndrome metabólica.

\section{REFERENCES}

1. Alva ML, Gray A, Mihaylova B, Leal J, Holman RR. The impact of diabetes-related complications on healthcare costs: new results from the UKPDS (UKPDS 84). Diabet Med. 2015;32(4):459-66.

2. Kozakowski J, Gietka-Czernel M, Leszczyńska D, Majos A. Obesity in menopause - our negligence or an unfortunate inevitability? Prz Menopauzalny. 2017;16(2):61-5.

3. Tuomikoski P, Savolainen-Peltonen H. Vasomotor symptoms and metabolic syndrome. Maturitas. 2017;97:61-5.

4. Gartoulla P, Worsley R, Bell RI, Davis SR. Moderate to severe vasomotor and sexual symptoms remain problematic for women aged 60 to 65 years. Menopause. 2015;22(7):694-701.

5. Mishra GD, Dobson AJ. Using longitudinal profiles to characterize women's symptoms through midlife: results from a large prospective study. Menopause. 2012;19(5):549-55.

6. Harlow SD, Gass M, Hall JE, Lobo R, Maki P, Rebar RW, et al. Executive summary of the Stages of Reproductive Aging Workshop + 10: addressing the unfinished agenda of staging reproductive aging. | Clin Endocrinol Metab. 2012;97(4):1159-68.

7. Pinkerton JV, Abraham L, Bushmakin AG, Cappelleri JC, Komm BS Relationship between changes in vasomotor symptoms and changes in menopause-specific quality of life and sleep parameters. Menopause. 2016;23(10):1060-6.

8. Charkoudian N, Hart EC|, Barnes (N, Joyner MI. Autonomic control of body temperature and blood pressure: influences of female sex hormones. Clin Auton Res. 2017;27(3):149-55.

9. Lambert E, Straznicky N, Sari Cl, Eikelis N, Hering D, Head G, et al. Dyslipidemia is associated with sympathetic nervous activation and impaired endothelial function in young females. Am J Hypertens. 2013;26(2):250-6.

10. Thurston RC, Sutton-Tyrrel K, Everson-Rose SA, Hess R, Matthews KA Hot flashes and subclinical cardiovascular disease: findings from the Study of Women's Health Across the Nation Heart Study. Circulation. 2008;118(12):1234-40.

11. Jackson EA, El Khoudary SR, Crawford SL, Matthews $\mathrm{K}$, loffe H, Chae $\mathrm{C}$, et al. Hot flash frequency and blood pressure: data from the Study of Women's Health Across the Nation. J Womens Health (Larchmt). 2016;25(12):1204-9.

12. Lee SW, Jo HH, Kim MR, Kwon DI, You YO, Kim JH. Association between menopausal symptoms and metabolic syndrome in postmenopausal women. Arch Gynecol Obstet. 2012;285(2):541-8.

13. Ryu KJ, Park HT, Kwon DH, Yang KS, Kim YJ, Yi KW, et al. Vasomotor symptoms and metabolic syndrome in Korean postmenopausal women. Menopause. 2015;22(11):1239-45.
14. Schmitt AC, Cardoso MR, Lopes H, Pereira WM, Pereira EC, Rezende DA et al. Prevalence of metabolic syndrome and associated factors in women aged 35 to 65 years who were enrolled in a family health program in Brasil. Menopause. 2013;20(4):470-6.

15. Fonseca AM, Bagnoli VR, Souza MA, Azevedo RS, Couto |r EB, Soares |r $J M$, et al. Impact of age and body mass on the intensity of menopausal symptoms in 5968 Brazilian women. Gynecol Endocrinol. 2013;29(2):116-8.

16. Sarrel P, Portman D, Lefebvre P, Lafeuille MH, Grittner AM, Fortier |. Incremental direct and indirect costs of untreated vasomotor symptoms. Menopause. 2015;22(3):260-6.

17. Associação Brasileira para o Estudo da Obesidade e da Síndrome Metabólica. Diretrizes Brasileiras de Obesidade 2016. $4^{\mathrm{a}}$ ed. São Paulo: ABESO; 2016.

18. Expert Panel on Detection, Evaluation, and Treatment of High Blood Cholesterol in Adults. Executive Summary of The Third Report of The National Cholesterol Education Program (NCEP). Expert panel on detection, evaluation, and treatment of high blood cholesterol in adults (Adult Treatment Panel III). JAMA. 2001;285(19):2486-97.

19. BRASIL. Conselho Nacional de Saúde. Resolução 466/12. Trata de pesquisas em seres humanos e atualiza a resolução 196. [Internet]. Diário Oficial da União, 2012. [cited 2018, April 5]. Available from: http://conselho.saude. gov.br/resolucoes/2012/Reso466.pdf

20. Sorpreso IC, Soares Júnior IM, Fonseca AM, Baracat EC. Female aging. Rev Assoc Med Bras. 2015;61(6):553-6.

21. Iwase $S$, Mano T, Watanabe T, Saito M, Kobayashi F. Age-related changes of sympathetic outflow to muscles in humans. J Gerontol. 1991;46(1):M1-5.

22. Silva NL, Boulant |A. Effects of testosterone, estradiol, and temperature on neurons in preoptic tissue slices. Am J Physiol. 1986;250(4 Pt 2):R625-32.

23. Mancini MC. Tratado de obesidade. $2^{\mathrm{a}}$ ed. Rio de Janeiro: Guanabara Koogan; 2004.

24. Freedman RR. Menopausal hot flashes: mechanisms, endocrinology, treatment. J Steroid Biochem Mol Biol. 2014;142:115-20.

25. Gordon JL, Rubinow DR, Thurston RC, Paulson J, Schmidt PJ, Girdler SS. Cardiovascular, hemodynamic, neuroendocrine, and inflammatory markers in women with and without vasomotor symptoms. Menopause. 2016;23(11):1189-98

26. Saccomani S, Lui-Filho JF, Juliato CR, Gabiatti JR, Pedro AO, Costa-Paiva $L$. Does obesity increase the risk of hot flashes among midlife women?: population-based study. Menopause. 2017;24(9):1065-70. 